\title{
Parameter Optimization of Wire EDM for H-13 Tool Steel
}

\author{
Satish Giduturi* and Ashok Kumar \\ Department of Mechanical Engineering, Ambala College of Engineering and Applied Research, Kurukshetra University, Haryana, India
}

Received 15 Dec 2017, Accepted 15 Feb 2018, Available online 22 Feb 2018, Vol.8, No.1 (Jan/Feb 2018)

\begin{abstract}
Wire Electrical Discharge Machining (WEDM) is a widely accepted non-traditional material removal process used to manufacture components with intricate shapes and profiles. It is considered as a unique adaptation of the conventional EDM process, which uses an electrode to initialize the sparking process. H13 Hot Work Tool Steel has high hot tensile strength, hot wear-resistance and toughness. Good thermal conductivity and insensitiveness to hot cracking, making it suitable not only for hot die applications but also plastic moulds. In this study, it is found that most predominant factors for the maximum material removal rate which is $22.21 \mathrm{~mm} 3 / \mathrm{min}$ are current which was

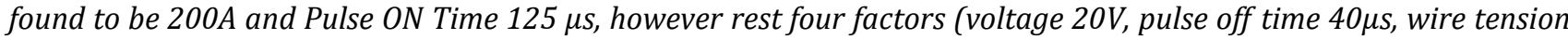
$8 \mathrm{~N}$ and wire feed $7 \mathrm{~mm} / \mathrm{min}$ ) has less impact as compare to the predominant factors. The most predominant factors for Minimum surface roughness which is $0.89 \mu \mathrm{m}$ are wire tension $10 \mathrm{~N}$, pulse on time $115 \mu$ s and servo voltage $60 \mathrm{~V}$. However, rest three factors pulse off time $60 \mu \mathrm{s}$, peak current $140 \mathrm{~A}$ and wire feed $7 \mathrm{~mm} / \mathrm{min}$ has less impact as compare to the predominant factors.
\end{abstract}

Keywords: WEDM; Taguchi Method, ANOVA, TON; TOFF; MRR; WT; WF; SV; IP

\section{Introduction}

Wire electrical discharge machining (WEDM) is a specialized thermal machining process capable of accurately machining parts with varying hardness or complex shapes, which have sharp edges that are very difficult to be machined by the main stream machining processes. It is a widely accepted non-traditional material removal process used to manufacture components with intricate shapes and profiles. It is considered as a unique adaptation of the conventional EDM process, which uses an electrode to initialize the sparking process. However, WEDM in figure 1 utilizes a continuously traveling wire electrode made of thin copper, brass or tungsten of diameter 0.05-0.3 mm, which is capable of achieving very small corner radii. The wire is kept in tension using a mechanical tensioning device reducing the tendency of producing inaccurate parts. During the WEDM process, the material is eroded ahead of the wire and there is no direct contact between the work piece and the wire, eliminating the mechanical stresses during machining. In addition, the WEDM process is able to machine exotic and high strength and temperature resistive (HSTR) materials and eliminate the geometrical changes occurring in the machining of heat-treated steels.

*Corresponding author Satish Giduturi is a PG Scholar (ORCID ID: 0000-0002-7673-753) and Ashok Kumar is working as Assistant Professor, DOI: https://doi.org/10.14741/ijcet/v.8.1.24

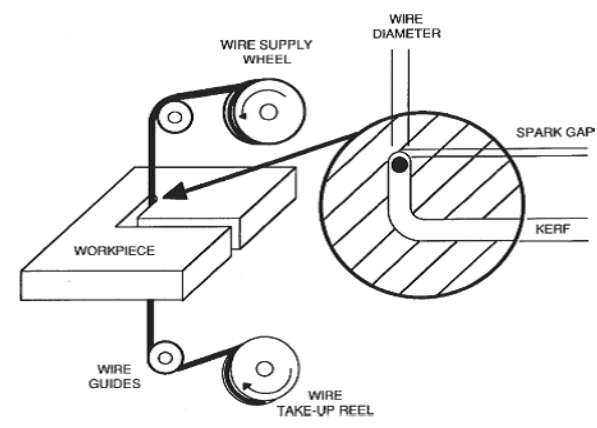

Figure 1: Wire Electric Discharge Machining

The material removal mechanism of WEDM is very similar to the conventional EDM Process involving the erosion effect of produced by the electrical discharge (sparks). In WEDM, material is eroded from the work piece by a series of discrete sparks occurring between the work piece and the wire separated by a stream of dielectric fluid, which is continuously fed to the machining zone. The basic scheme of Wire electric discharge machining is illustrated in figure 2 However, today's WEDM process is commonly conducted on the work piece that are totally submerged in a tank filled with dielectric fluid. Such a submerged method of WEDM promotes temperature stabilization and efficient flushing especially in cases where the work piece has varying thickness. The WEDM process make use of electrical Energy generating a channel of plasma between the cathode and anode, and turns into thermal 
energy at a temperature in the range between of 8000$12000^{\circ} \mathrm{C}$ or as high as $20,000^{\circ} \mathrm{C}$ initializing a substantial amount of heating and melting of material on the surface of each pole. When the pulsating direct current power supply occurring between 20,000 and $30,000 \mathrm{~Hz}$ is turned off, the plasma channel breaks down. This causes a sudden reduction in the temperature allowing the circulating dielectric fluid to implore the plasma channel and plush the molten particle from the pole surface in the form of microscopic debris.
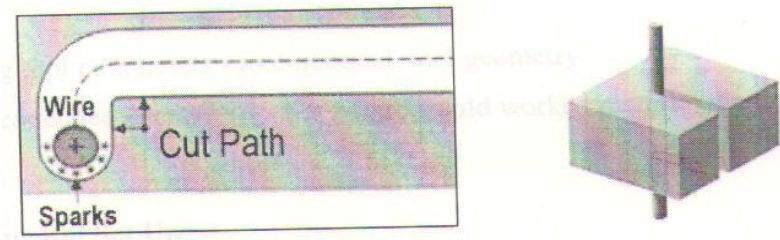

Figure 2: Wire Electric Discharge Machining Process

\section{Materials and methods}

\subsection{Work Material}

H13 Hot Work Tool Steel has high hot tensile strength, hot wear-resistance and toughness. Good thermal conductivity and insensitiveness to hot cracking. H13 type grade offers a good resistance to softening, up to $600^{\circ} \mathrm{C}$, combined with good stability in hardening and high toughness, making it suitable not only for hot die applications but also for plastic moulds. It has many applications for making Hot punches and dies for blanking, bending, swaging and forging, hot extrusion dies for aluminum cores, ejector pins, inserts and nozzles for aluminum, tin and lead die casting. The table 1 shows the chemical composition of $\mathrm{H}-13$ Hot Tool Steel.

Table 1: Chemical composition of H-13 Hot Tool Steel

\begin{tabular}{|c|c|c|}
\hline \multirow{4}{*}{$\begin{array}{c}\text { Spectro Analysis } \\
\text { Test Report }\end{array}$} & Sr No. & 1 \\
\cline { 2 - 3 } & Material & H13 \\
\cline { 2 - 3 } & Carbon(\%) & 0.316 \\
\cline { 2 - 3 } & Manganese(\%) & 0.338 \\
\cline { 2 - 3 } & Phosphorus(\%) & 0.0125 \\
\cline { 2 - 3 } & Sulphur(\%) & 0.0134 \\
\cline { 2 - 3 } & Silicon(\%) & 0.8025 \\
\cline { 2 - 3 } & Chromium(\%) & 4.956 \\
\cline { 2 - 3 } & Vanadium(\%) & 1.09 \\
\cline { 2 - 3 } & Molydeum(\%) & 1.285 \\
\hline
\end{tabular}

\subsection{Schematic of machining}

The experiments were carried out on a wire-cut EDM machine (fig 3) ELEKTRA SPRINTCUT 734. The WEDM machine tool has the following specifications:

Design: Fixed column, moving table

Table size: 440 x $650 \mathrm{~mm}$

Max. workpiece height: $200 \mathrm{~mm}$
Max. workpiece weight : $500 \mathrm{~kg}$

Main table traverse (X, Y) : 300, $400 \mathrm{~mm}$

Auxiliary table traverse $(\mathrm{u}, \mathrm{v}): 80,80 \mathrm{~mm}$

Wire electrode diameter: $0.25 \mathrm{~mm}$ (Standard)

Generator: ELPULS-40 A DLX

Controlled axes: X, Y, U, V

Simultaneous / independent

Interpolation: Linear \& Circular

Input Power supply : 3 phase, AC $415 \mathrm{~V}, 50 \mathrm{~Hz}$

Connected load: $10 \mathrm{KVA}$

Average power consumption: 6 to 7 KVA

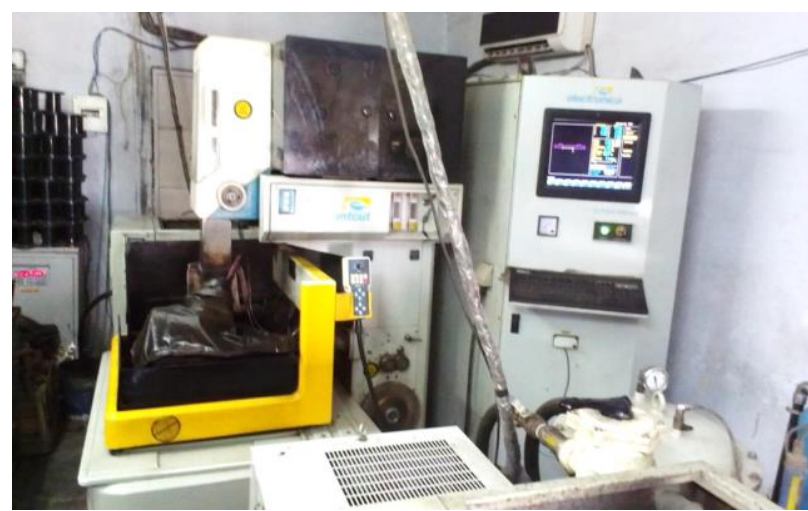

Figure 3: Elektra Sprintcut 734

\subsection{Experimentation Methods}

In this experiment Taguchi's L18 orthogonal array method is being used. The results are being analysed by using ANOVA method and Signal to Noise ratios are used to optimize the objective parameters.

\section{Measurement of experimental parameters}

\subsection{Cutting Rate}

For WEDM, cutting rate is a desirable characteristic and it should be as high as possible to give least machine cycle time leading to increased productivity. In the present study cutting rate is a measure of job cutting which is digitally displayed on the screen of the machine and is given quantitatively in $\mathrm{mm} / \mathrm{min}$.

\subsection{Surface Roughness}

Roughness is often a good predictor of the performance of a mechanical component, since irregularities in the surface may form nucleation sites for cracks or corrosion. Roughness is a measure of the texture of a surface. It is quantified by the vertical deviations of a real surface from its ideal form. If these deviations are large, the surface is rough; if small, the surface is smooth. Roughness is typically considered to be the high frequency, short wavelength component of a measured surface. The parameter mostly used for general surface roughness is Ra. It measures average roughness by comparing all the peaks and valleys to the mean line, and then averaging them all over the 
entire cut-off length. In this work the surface roughness was measured by MarSurf PS1 (Fig.4.7). The MarSurf PS1 is a shop-floor type surfaceroughness measuring instrument, which traces the surface of various machine parts and calculates the surface roughness based on roughness standards, and displays the results in $\mu \mathrm{m}$.

Input process parameters such as Wire Tension (A), Wire Feed (B), Pulse-on time (C), Pulse-off time (D), Servo Voltage (E) and Peak current (F) used in this study are shown in Table 2. Gap Voltage in the range of 20 to 60 Volts; T on in the range of 115 to 125 ; T off in the range of 40 to 60 ; Peak current in the range of 140 to 200 amps. To perform the experimental design, two levels of machining parameter of Wire Tension and three levels of each machining parameters (Wire Feed, Ton, Toff, Gap Voltage and Gap Current) were selected as shown in table 2 .

Table 2: Process Parameters and their Ranges

\begin{tabular}{|c|c|c|c|c|c|}
\hline $\begin{array}{c}\text { Process } \\
\text { Parameters }\end{array}$ & Symbols & $\begin{array}{c}\text { Process } \\
\text { Designation }\end{array}$ & $\begin{array}{c}\text { Level } \\
\mathbf{1}\end{array}$ & $\begin{array}{c}\text { Level } \\
\mathbf{2}\end{array}$ & $\begin{array}{c}\text { Level } \\
\mathbf{3}\end{array}$ \\
\hline $\begin{array}{c}\text { Wire } \\
\text { Tension }\end{array}$ & WT & A & 8 & 10 & - \\
\hline Wire Feed & WF & B & 7 & 8 & 9 \\
\hline
\end{tabular}

\begin{tabular}{|c|c|c|c|c|c|}
\hline $\begin{array}{c}\text { Pulse-on } \\
\text { Time }\end{array}$ & T on & C & 115 & 120 & 125 \\
\hline $\begin{array}{c}\text { Pulse-off } \\
\text { Time }\end{array}$ & T off & D & 40 & 50 & 60 \\
\hline $\begin{array}{c}\text { Servo } \\
\text { voltage }\end{array}$ & SV & E & 20 & 40 & 60 \\
\hline Peak current & IP & F & 140 & 170 & 200 \\
\hline
\end{tabular}

\section{Data analysis and discussion}

An L18 orthogonal array is used to specify the experiments. To take in to account the effect of noise factors and to study the nonlinear relationship among the process variables, five values of cutting speeds were taken at each work piece sample of area $5 \times 5$ $\mathrm{mm}^{2}$. The cutting speeds \& MRR for the H13 Material is shown in Table $3 \&$ the value of Surface Roughness (Ra) by using MarSurf PS1 is shown in Table 4. S/N data of the MRR \& Ra are also given in table 5. The signals to noise ratio $(\mathrm{S} / \mathrm{N})$ ratio of the individual runs, which is calculated as:

$\mathrm{S} / \mathrm{N}=-10 \log 1 / \mathrm{R}\left\{\sum_{j=1}^{R} \quad\left(\mathrm{y}_{\mathrm{i}}-\mathrm{y}_{\mathrm{o}}\right)\right\}$

Where $\mathrm{y}_{\mathrm{i}}$ is the individual cutting speed in a run

Table 3: MRR value for the H13 Material

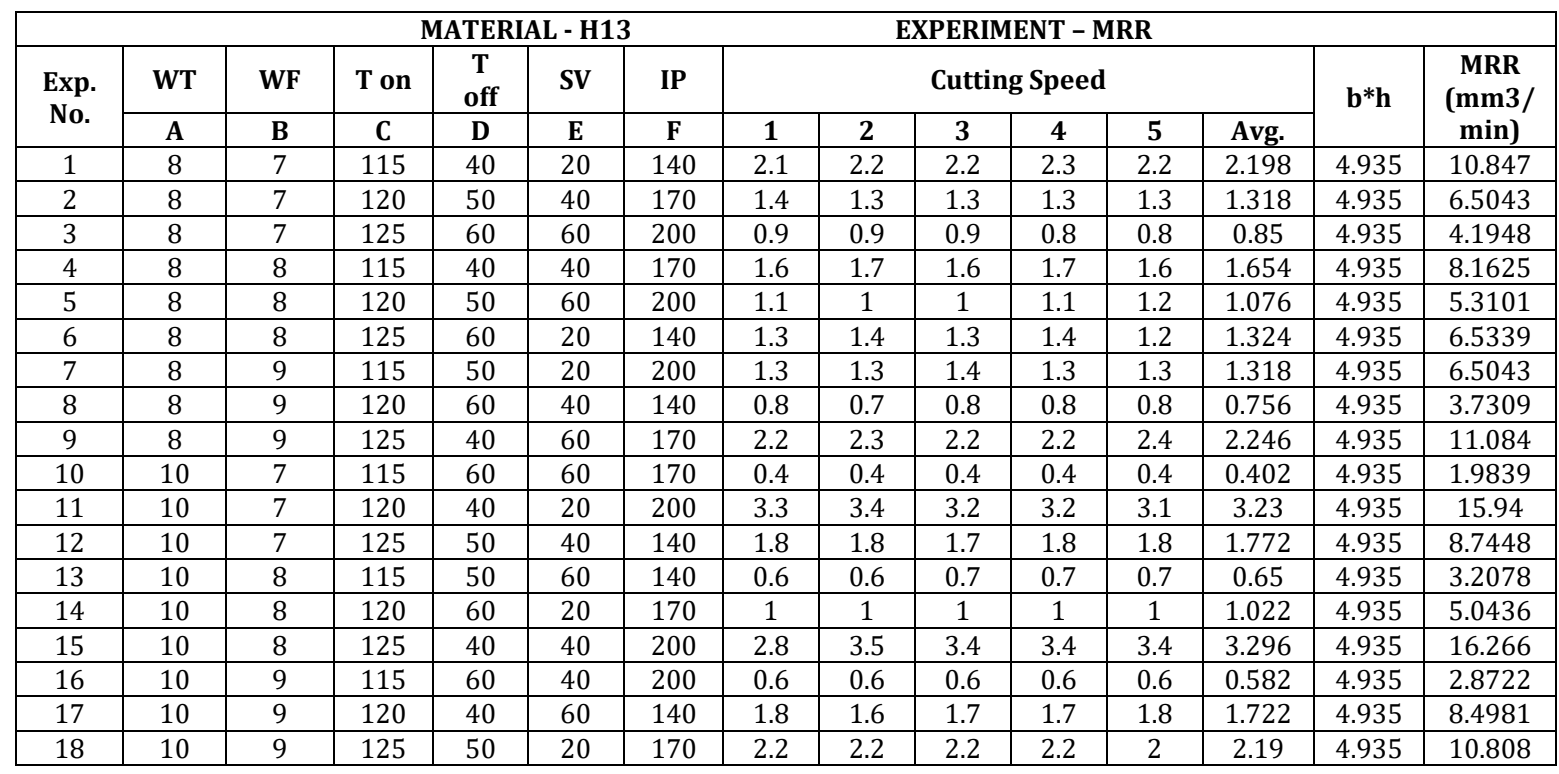

Table 4: Ra value for the H13 Material

\begin{tabular}{|c|c|c|c|c|c|c|c|c|c|c|}
\hline $\begin{array}{c}\text { Exp. } \\
\text { No. }\end{array}$ & WT & WF & T on & T off & SV & IP & \multicolumn{4}{|c|}{ Ra in $\boldsymbol{\mu m}$} \\
\hline & A & B & C & D & E & F & 1 & 2 & 3 & Avg.Ra \\
\hline 1 & 8 & 7 & 115 & 40 & 20 & 140 & 1.422 & 1.937 & 1.624 & 1.661 \\
\hline 2 & 8 & 7 & 120 & 50 & 40 & 170 & 2.985 & 2.842 & 2.926 & 2.918 \\
\hline 3 & 8 & 7 & 125 & 60 & 60 & 200 & 1.791 & 1.882 & 1.918 & 1.864 \\
\hline 4 & 8 & 8 & 115 & 40 & 40 & 170 & 4.12 & 4.068 & 3.986 & 4.058 \\
\hline 5 & 8 & 8 & 120 & 50 & 60 & 200 & 3.02 & 2.287 & 2.118 & 2.475 \\
\hline 6 & 8 & 8 & 125 & 60 & 20 & 140 & 2.426 & 2.888 & 2.929 & 2.748 \\
\hline 7 & 8 & 9 & 115 & 50 & 20 & 200 & 4.191 & 4.086 & 4.242 & 4.173 \\
\hline 8 & 8 & 9 & 120 & 60 & 40 & 140 & 1.721 & 1.928 & 1.884 & 1.844 \\
\hline 9 & 8 & 9 & 125 & 40 & 60 & 170 & 4.022 & 3.901 & 3.886 & 3.936 \\
\hline 10 & 10 & 7 & 115 & 60 & 60 & 170 & 1.386 & 1.428 & 2.02 & 1.611 \\
\hline 11 & 10 & 7 & 120 & 40 & 20 & 200 & 3.621 & 3.524 & 3.432 & 3.526 \\
\hline
\end{tabular}




\begin{tabular}{|l|l|l|l|l|l|l|l|l|l|l|}
\hline 12 & 10 & 7 & 125 & 50 & 40 & 140 & 1.006 & 2.021 & 1.886 & 1.638 \\
\hline 13 & 10 & 8 & 115 & 50 & 60 & 140 & 1.553 & 1.448 & 1.582 & 1.528 \\
\hline 14 & 10 & 8 & 120 & 60 & 20 & 170 & 2.999 & 3.062 & 3.122 & 3.061 \\
\hline 15 & 10 & 8 & 125 & 40 & 40 & 200 & 3.802 & 3.718 & 3.666 & 3.729 \\
\hline 16 & 10 & 9 & 115 & 60 & 40 & 200 & 1.75 & 1.862 & 2.12 & 1.911 \\
\hline 17 & 10 & 9 & 120 & 40 & 60 & 140 & 2.95 & 2.768 & 2.786 & 2.835 \\
\hline 18 & 10 & 9 & 125 & 50 & 20 & 170 & 5.026 & 4.998 & 4.912 & 4.979 \\
\hline
\end{tabular}

Table 5: S/N data of the MRR \& Ra for the Material H13

\begin{tabular}{|c|c|c|c|c|c|c|c|c|c|c|}
\hline \multirow{2}{*}{ Exp. No. } & WT & WF & $\mathrm{T}$ on & T off & SV & IP & & & & \\
\hline & $\mathrm{A}$ & $\mathrm{B}$ & $\mathrm{C}$ & $\mathrm{D}$ & $E$ & $F$ & MRR & $\mathrm{S} / \mathrm{N}$ ratio & $\mathrm{Ra}(\mu \mathrm{m})$ & $\mathrm{S} / \mathrm{N}$ ratio \\
\hline 1 & 8 & 7 & 115 & 40 & 20 & 140 & 10.85 & 20.71 & 1.661 & -4.407 \\
\hline 2 & 8 & 7 & 120 & 50 & 40 & 170 & 6.504 & 16.26 & 2.918 & -9.301 \\
\hline 3 & 8 & 7 & 125 & 60 & 60 & 200 & 4.195 & 12.45 & 1.864 & -5.407 \\
\hline 4 & 8 & 8 & 115 & 40 & 40 & 170 & 8.162 & 18.24 & 4.058 & -12.166 \\
\hline 5 & 8 & 8 & 120 & 50 & 60 & 200 & 5.31 & 14.5 & 2.475 & -7.872 \\
\hline 6 & 8 & 8 & 125 & 60 & 20 & 140 & 6.534 & 16.3 & 2.748 & -8.779 \\
\hline 7 & 8 & 9 & 115 & 50 & 20 & 200 & 6.504 & 16.26 & 4.173 & -12.409 \\
\hline 8 & 8 & 9 & 120 & 60 & 40 & 140 & 3.731 & 11.44 & 1.844 & -5.317 \\
\hline 9 & 8 & 9 & 125 & 40 & 60 & 170 & 11.08 & 20.89 & 3.936 & -11.902 \\
\hline 10 & 10 & 7 & 115 & 60 & 60 & 170 & 1.984 & 5.95 & 1.611 & -4.144 \\
\hline 11 & 10 & 7 & 120 & 40 & 20 & 200 & 15.94 & 24.05 & 3.526 & -10.945 \\
\hline 12 & 10 & 7 & 125 & 50 & 40 & 140 & 8.745 & 18.84 & 1.638 & -4.285 \\
\hline 13 & 10 & 8 & 115 & 50 & 60 & 140 & 3.208 & 10.12 & 1.528 & -3.681 \\
\hline 14 & 10 & 8 & 120 & 60 & 20 & 170 & 5.044 & 14.06 & 3.061 & -9.717 \\
\hline 15 & 10 & 8 & 125 & 40 & 40 & 200 & 16.27 & 24.23 & 3.729 & -11.431 \\
\hline 16 & 10 & 9 & 115 & 60 & 40 & 200 & 2.872 & 9.164 & 1.911 & -5.624 \\
\hline 17 & 10 & 9 & 120 & 40 & 60 & 140 & 8.498 & 18.59 & 2.835 & -9.05 \\
\hline 18 & 10 & 9 & 125 & 50 & 20 & 170 & 10.81 & 20.68 & 4.979 & -13.942 \\
\hline
\end{tabular}

\subsection{Analysis of Material Removal Rate Values for H13 Tool Steel}

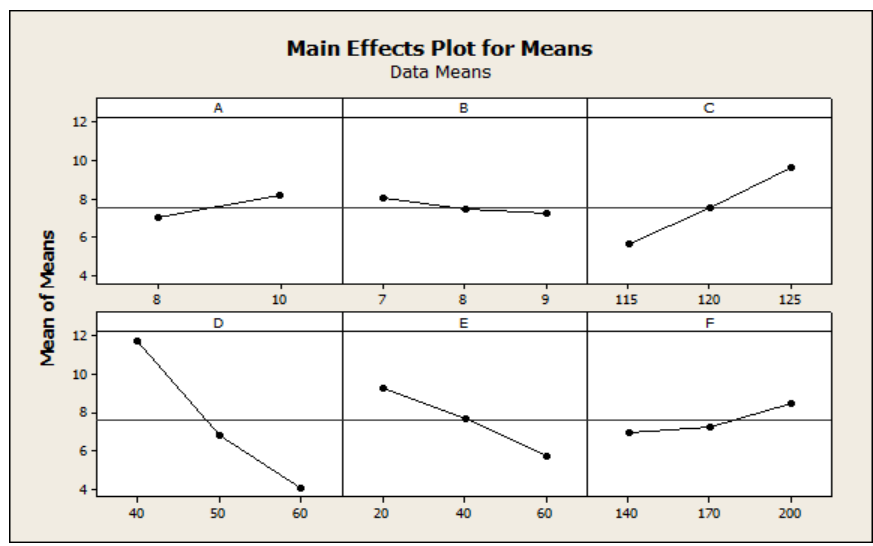

Figure 4: Effects of Process Parameters on MRR for H13 Tool Steel

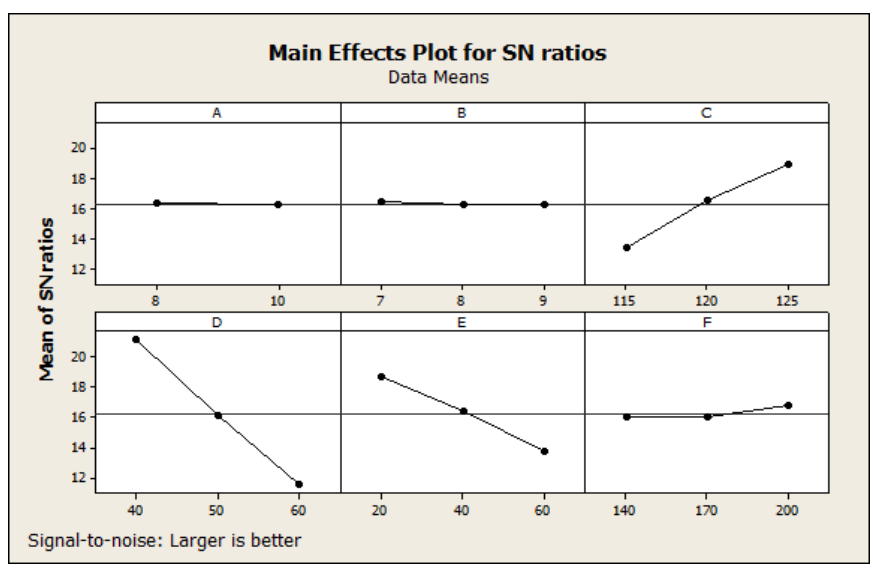

Figure 5: Effects of Process Parameters on MRR for H13 Tool Steel (S/N Data) 
The Fig 5 concluded that Parameters Wire Tension (A) and Wire Feed(B) were not highly contribute in MRR whereas by increasing the value of parameter Pulse ON Time (C) and Peak current (F) the MRR also increased $\&$ by increasing the value of parameter Pulse Off Time (D) \& Servo Voltage (E) the MRR decreased and this shows that A1, B1, C3, D1, E1 and F3 are the optimum factors.

$\eta_{\text {opt }}=m+(m A 1-m)+(m B 1-m)+(m C 3-m)+(m D 1-$

$m)+(m E 1-m)+(m F 3-m)$

As here $m=16.263$
Now by using the above relation and by putting the required values

$\eta_{\text {opt }}=26.74$

$\mathrm{y}_{\text {opt }}{ }^{2}=1 / 10$ - nopt $/ 10$

$\mathrm{y}_{\text {opt }}=21.72 \mathrm{~mm}^{3} / \mathrm{min}$

Now the above value of MRR was theoretical and also the above set of optimum factors not present in the used array table so to find out the practical value of MRR at above optimum factors an experiment was done on the workpiece and through this experiment the required corresponding value is $22.21 \mathrm{~mm}^{3} / \mathrm{min}$

Table 6: Analysis of Variance for $\mathrm{S} / \mathrm{N}$ ratios of MRR for $\mathrm{H} 13$

\begin{tabular}{|c|c|c|c|c|c|c|c|}
\hline Source & DF & Seq SS & Adj SS & Adj MS & F & P & PC(\%) \\
\hline A & 1 & 0.108 & 0.108 & 0.108 & 1.8 & 0.229 & 0.0245 \\
\hline B & 2 & 0.132 & 0.132 & 0.066 & 1.1 & 0.393 & 0.02994 \\
\hline C & 2 & 90.862 & 90.862 & 45.431 & 753.31 & 0.000 & 20.6124 \\
\hline D & 2 & 274.153 & 274.153 & 137.077 & 2272.91 & 0.000 & 62.1927 \\
\hline E & 2 & 72.815 & 72.815 & 36.4075 & 603.68 & 0.000 & 16.5184 \\
\hline F & 2 & 2.379 & 2.379 & 1.1895 & 19.73 & 0.002 & 0.53969 \\
\hline Residual error & 6 & 0.362 & 0.362 & 0.06033 & & & 0.08212 \\
\hline Total & 17 & 440.812 & & & & & \\
\hline
\end{tabular}

Table 7: Analysis of Variance for Means of MRR for H13

\begin{tabular}{|c|c|c|c|c|c|c|c|}
\hline Source & DF & Seq SS & Adj SS & Adj MS & F & P & PC (\%) \\
\hline A & 1 & 6.115 & 6.115 & 6.115 & 4.860 & 0.070 & 2.072 \\
\hline B & 2 & 2.052 & 2.052 & 1.026 & 0.820 & 0.486 & 0.695 \\
\hline C & 2 & 48.250 & 48.250 & 24.125 & 19.180 & 0.002 & 16.350 \\
\hline D & 2 & 184.404 & 184.404 & 92.202 & 73.300 & 0.000 & 62.487 \\
\hline E & 2 & 38.345 & 38.345 & 19.173 & 15.240 & 0.004 & 12.994 \\
\hline F & 2 & 8.393 & 8.393 & 4.197 & 3.340 & 0.106 & 2.844 \\
\hline Residual error & 6 & 7.547 & 7.547 & 1.258 & & & 2.557 \\
\hline Total & 17 & 295.107 & & & & & \\
\hline
\end{tabular}

Table 8: Response Table for Signal to Noise Ratios of MRR for H13 Larger is better

\begin{tabular}{|c|c|c|c|c|c|c|}
\hline Level & A & B & C & D & F & 18.68 \\
\hline 1 & 16.34 & 16.38 & 13.41 & 21.12 & 16 \\
\hline 2 & 16.18 & 16.24 & 16.48 & 16.11 & 16.36 \\
\hline 3 & & 16.17 & 18.9 & 11.56 & 13.75 \\
\hline Delta & 0.16 & 0.21 & 5.49 & 9.56 & 4.92 \\
\hline Rank & 6 & 5 & 2 & 1 & 3 \\
\hline
\end{tabular}

Table 9: Response Table for Means of MRR for H13

\begin{tabular}{|c|c|c|c|c|c|c|}
\hline Level & A & B & C & D & $\mathrm{E}$ & F \\
\hline 1 & 6.986 & 8.036 & 5.596 & 11.8 & 9.279 & 6.927 \\
\hline 2 & 8.152 & 7.421 & 7.504 & 6.846 & 7.713 & 7.264 \\
\hline 3 & & 7.25 & 9.605 & 4.06 & 5.713 & 8.515 \\
\hline Delta & 1.166 & 0.786 & 4.009 & 7.74 & 3.566 & 1.587 \\
\hline Rank & 5 & 6 & 2 & 1 & 3 & 4 \\
\hline
\end{tabular}


5.2 Analysis of Surface Roughness Values for H13 Tool Steel

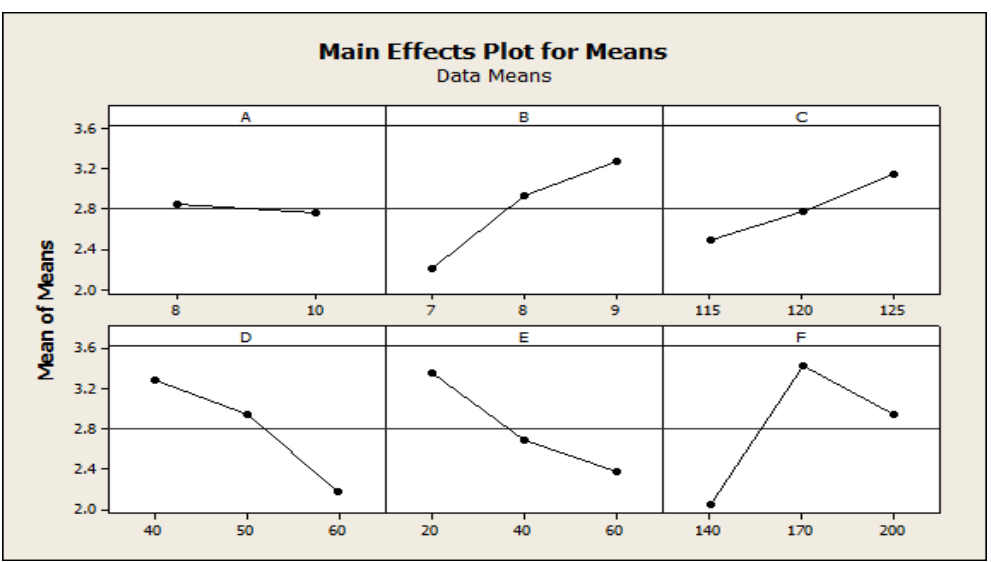

Figure 6: Effects of Process Parameters on Surface Roughness for H13 Tool Steel

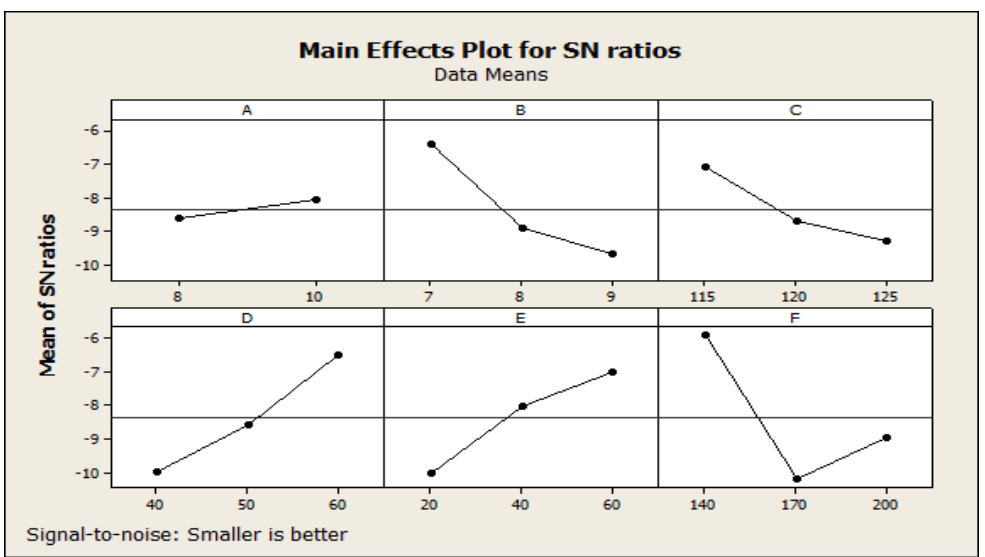

Figure 7: Effects of Process Parameters on Surface Roughness for H13 Tool Steel

Table 10: Analysis of Variance for $\mathrm{S} / \mathrm{N}$ ratios of $\mathrm{Ra}$ for $\mathrm{H} 13$

\begin{tabular}{|c|c|c|c|c|c|c|c|}
\hline Source & DF & Seq SS & Adj SS & Adj MS & F & P & PC $(\%)$ \\
\hline A & 1 & 1.249 & 1.249 & 1.249 & 0.48 & 0.514 & 0.65157 \\
\hline B & 2 & 35.619 & 35.619 & 17.8095 & 6.85 & 0.028 & 18.5815 \\
\hline C & 2 & 15.852 & 15.852 & 7.926 & 3.05 & 0.122 & 8.26956 \\
\hline D & 2 & 36.911 & 36.911 & 18.4555 & 7.1 & 0.026 & 19.2555 \\
\hline E & 2 & 28.44 & 28.44 & 14.22 & 5.47 & 0.044 & 14.8364 \\
\hline F & 2 & 58.013 & 58.013 & 29.0065 & 11.15 & 0.010 & 30.2638 \\
\hline $\begin{array}{c}\text { Residual } \\
\text { error }\end{array}$ & 6 & 15.607 & 15.607 & 2.60117 & & & \\
\hline \begin{tabular}{c} 
Total \\
\hline
\end{tabular} & 17 & 191.691 & & & & \\
\hline
\end{tabular}

Table 11: Analysis of Variance for Means of Ra for H13

\begin{tabular}{|c|c|c|c|c|c|c|c|}
\hline Source & DF & Seq SS & Adj SS & Adj MS & F & P & PC (\%) \\
\hline A & 1 & 0.041 & 0.041 & 0.041 & 0.170 & 0.696 & 0.213 \\
\hline B & 2 & 3.626 & 3.626 & 1.813 & 7.430 & 0.024 & 18.739 \\
\hline C & 2 & 1.308 & 1.308 & 0.654 & 2.680 & 0.147 & 6.762 \\
\hline D & 2 & 3.940 & 3.940 & 1.970 & 8.070 & 0.020 & 20.366 \\
\hline E & 2 & 3.034 & 3.034 & 1.517 & 6.220 & 0.034 & 15.681 \\
\hline F & 2 & 5.934 & 5.934 & 2.967 & 12.160 & 0.008 & 30.669 \\
\hline $\begin{array}{c}\text { Residual } \\
\text { error }\end{array}$ & 6 & 1.464 & 1.464 & 0.244 & & & 7.568 \\
\hline Total & 17 & 19.347 & & & & \\
\hline
\end{tabular}


Table 12: Response Table for Signal to Noise Ratios of Ra for H13 Smaller is better

\begin{tabular}{|c|c|c|c|c|c|c|}
\hline Level & A & B & C & D & E & F \\
\hline 1 & -8.618 & -6.415 & -7.072 & -9.984 & -10.033 & -5.92 \\
\hline 2 & -8.091 & -8.941 & -8.7 & -8.581 & -8.021 & -10.195 \\
\hline 3 & & -9.707 & -9.291 & -6.498 & -7.009 & -8.948 \\
\hline Delta & 0.527 & 3.393 & 2.219 & 3.486 & 3.024 & 4.276 \\
\hline Rank & 6 & 3 & 5 & 2 & 4 & 1 \\
\hline
\end{tabular}

Table 13: Response Table for Means of Ra for H13

\begin{tabular}{|c|c|c|c|c|c|c|}
\hline Level & A & B & C & D & E & 3.358 \\
\hline 1 & 2.853 & 2.203 & 2.49 & 3.291 & 2.042 \\
\hline 2 & 2.757 & 2.933 & 2.776 & 2.952 & 2.683 & 3.427 \\
\hline 3 & & 3.28 & 3.149 & 2.173 & 2.375 & 0.983 \\
\hline Delta & 0.096 & 1.077 & 0.659 & 1.118 & 1.385 \\
\hline Rank & 6 & 3 & 5 & 2 & 4 \\
\hline
\end{tabular}

The Fig. 6 concluded that by increasing the parameters wire Tension (A), Pulse off time (D) \& Servo voltage (E) the value of Ra decreased whereas by increasing the Value of Parameters Wire Feed (B), Pulse ON Time (C) \& Peak current (F) the value of Ra increased and this shows that A2, B1, C1, D3, E3 and F1 are the optimum factors.

$\eta_{\text {opt }}=m+(m A 2-m)+(m B 1-m)+(m C 1-m)+(m D 3-$

$m)+(m E 3-m)+(m F 1-m)$

As here $m=-8.355$

Now by using the above relation and by putting the required values

$$
\begin{aligned}
& \eta_{\text {opt }}=0.77 \\
& \mathrm{y}_{\text {opt }}^{2}=10^{-} \text {пopt } / 10 \\
& \mathrm{y}_{\text {opt }}=0.92 \mu \mathrm{m}
\end{aligned}
$$

Now the above value of Ra was theoretical and also the above set of optimum factors not present in the used array table so to find out the practical value of $\mathrm{Ra}$ at above optimum factors an experiment was done on the workpiece and through this experiment the required corresponding value is $0.89 \mu \mathrm{m}$.

\section{Conclusions}

\section{(a) Conclusion for MRR}

1) The pulse on time parameter has direct effect on the material removal rate, as the pulse on time increased the material removal rate also increased.

2) When peak current is increased the material removal rate increased.

3) When the pulse off time is increased the material removal rate decreased.

4) When servo voltage increased the material removal rate decreased.

5) The parameter wire tension (WT) has small effect on the material removal rate.
6) The parameter wire feed (WF) has small effect on the material removal rate.

(b) Conclusion for Surface Roughness

1) When parameter pulse on time increased the value of Surface Roughness increased.

2) When the pulse off time increased the value of Surface Roughness is decreased.

3) The value of Surface Roughness is decreased by increasing servo voltage.

4) When parameter peak current increases the value of Surface Roughness increased.

5) When wire tension increased the value of Surface Roughness is decreased.

6) 6. When wire feed increased the value of Surface Roughness is increased.

\section{References}

Basil, K., Paul, J., \& Issac, J. M. (2013). Spark gap optimization of WEDM process on Ti6Al4V. International Journal of Engineering Science and Innovative Technology (IJESIT), 2(1), 364-369.

Goyat, L., Dudi, R., \& Sharma, N. (2013). Investigation of Process Parameters Contribution and their Modeling in WEDM for D-2 Tool Steel Using ANOVA. Global Journal of Engineering, Design and Technology, 2(3), 41-46.

Han, F., Zhang, J., \& Soichiro, I. (2007). Corner error simulation of rough cutting in wire EDM. Precision engineering, 31(4), 331-336.

Ikram, A., Mufti, N. A., Saleem, M. Q., \& Khan, A. R. (2013) Parametric optimization for surface roughness, kerf and MRR in wire electrical discharge machining (WEDM) using Taguchi design of experiment. Journal of Mechanical Science and Technology, 27(7), 2133-2141.

Kanlayasiri, K., \& Boonmung, S. (2007). An investigation on effects of wire-EDM machining parameters on surface roughness of newly developed DC53 die steel. Journal of Materials Processing Technology, 187, 26-29.

Klink, A., Guo, Y. B., \& Klocke, F. (2011). Surface integrity evolution of powder metallurgical tool steel by main cut and finishing trim cuts in wire-EDM. Procedia engineering, 19, 178-183. 
Kumar, K., \& Agarwal, S. (2012). Multi-objective parametric optimization on machining with wire electric discharge machining. The International Journal of Advanced Manufacturing Technology, 62(5), 617-633.

Lahane, S. D., Rodge, M. K., \& Sharma, S. B. (2012). Multiresponse optimization of Wire-EDM process using principal component analysis. IOSR Journal of Engineering (IOSRJEN), 2(8), 38-47.

Li, L., Guo, Y. B., Wei, X. T., \& Li, W. (2013). Surface integrity characteristics in wire-EDM of Inconel 718 at different discharge energy. Procedia CirP, 6, 220-225.

Maan, V., \& Chaudhary, A. (2013). Optimization of Wire Electric Discharge Machining Process of D-2 Steel using Response Surface Methodology. International Journal of Engineering Research and Applications, 3(3), 206-216.

Mahapatra, S. S., \& Patnaik, A. (2007). Optimization of wire electrical discharge machining (WEDM) process parameters using Taguchi method. The International Journal of Advanced Manufacturing Technology, 34(9), 911-925.

Newton, T. R., Melkote, S. N., Watkins, T. R., Trejo, R. M., \& Reister, L. (2009). Investigation of the effect of process parameters on the formation and characteristics of recast layer in wire-EDM of Inconel 718. Materials Science and Engineering: A, 513, 208-215.

Patel, A. J. (2013). Prof. Satyam Patel, Parametric optimization of Wire cut EDM machine on hard steel alloy with multiple quality characteristics. Patel et al. International Journal of Advanced Engineering Technology E-ISSN, 0976-3945.

Prajapati, S. B., \& Patel, N. S. (2013). Effect of process parameters on performance measures of wire EDM for AISI A2 tool steel. International Journal of Computational Engineering Research, 3(4), 274-278.
Ramakrishnan, R., \& Karunamoorthy, L. (2006). Multi response optimization of wire EDM operations using robust design of experiments. The International Journal of Advanced Manufacturing Technology, 29(1-2), 105-112.

Ramesh, S. Parametric Optimization of Wire Electrical Discharge Machining of Composite Material. International Journal of Advanced Research in Computer Engineering \& Technology, 1(3), 6-15.

Sachdeva, G., Khanna, R., Yadav, P., Nara, A., \& Singh, N. (2013). Experimental study of H-21 punching dies on wirecut electric discharge machine using Taguchi's method. International Journal of Scientific \& Engineering Research, 4(5), 559-567.

Shah, A., Mufti, N. A., Rakwal, D., \& Bamberg, E. (2011). Material removal rate, kerf, and surface roughness of tungsten carbide machined with wire electrical discharge machining. Journal of materials engineering and performance, 20(1), 71-76.

Shah, C. D., Mevada, J. R., \& Khatri, B. C. (2013). Optimization of process parameter of wire electrical discharge machine by response surface methodology on Inconel600. International Journal of Emerging Technology and Advanced Engineering, 3(4), 2250-2459.

Singh, H., \& Garg, R. (2009). Effects of process parameters on material removal rate in WEDM. Journal of Achievements in Materials and Manufacturing Engineering, 32(1), 70-74.

Tzeng, H. J., Yan, B. H., Hsu, R. T., \& Chow, H. M. (2007). Finishing effect of abrasive flow machining on micro slit fabricated by wire-EDM. The International Journal of Advanced Manufacturing Technology, 34(7-8), 649-656.

Weingärtner, E., Wegener, K., \& Kuster, F. (2012). Applying wire electrical discharge dressing (WEDD) to improve grinding performance of metal bounded diamond wheels. Procedia CIRP, 1, 365-370.

Yan, M. T., \& Chien, H. T. (2007). Monitoring and control of the micro wire-EDM process. International Journal of Machine Tools and Manufacture, 47(1), 148-157. 